\title{
Especificación de un modelo para el estudio del establecimiento de múltiples agendas de sustentabilidad hídrica.
}

\author{
Specification of a model for the study of the establishment of \\ multiple water sustainability agendas.
}

Esta obra está bajo una Licencia Creative Commons Atribución 4.0 Internacional. DOI: $10.32870 /$ sincronia.axxiii.n75.15a19

\section{Oscar Valdés-Ambrosio}

Facultad de Economía

Universidad Nacional Autónoma de México

oscarva@economia.unam.mx

(MÉXICO)

\section{Michiko Amemiya-Ramírez}

Facultad de Arquitectura

Universidad Nacional Autónoma de México amemiya@unam.mx

(MÉXICO)

\section{Cruz García-Lirios}

Facultad de Psicología

Universidad Nacional Autónoma de México

garcialirios@unam.mx

(MÉXICO)

Recibido: 03/09/2018

Revisado: $22 / 10 / 2018$

Aprobado: 16/11/2018

\section{RESUMEN}


El fenómeno conocido como establecimiento de la agenda que en sus inicios fue observado como el sesgo de la televisión, la radio o la prensa en relación con la propaganda del estado omnipresente, muy pronto fue abandonado para advertir la multiplicidad de agendas audiencias, dispositivos y redes que enmarcan un fenómeno multidimensional. se realizó un estudio no experimental, transversal y exploratorio con una selección no probabilística de fuentes indexadas a repositorios iberoamericanos como Dialnet, Latindex, Redalyc y Scielo, considerando el periodo de 1968 a 2018, así como las palabras claves, aunque la especificación se limitó al diseño de la investigación se sugiere la inclusión de la resiliencia como factor emergente de la agenda hídrica sustentable.

Palabras clave: Teledirección. Horizontalidad. Microsistema. Heurístico. Periferia.

\section{ABSTRACT}

The phenomenon known as the establishment of the agenda that in its beginnings was observed as the bias of television, radio or the press in relation to the propaganda of the omnipresent state, was soon abandoned to warn of the multiplicity of agendas. and networks that frame a multidimensional phenomenon. a non-experimental, cross-sectional and exploratory study was carried out with a nonprobabilistic selection of sources indexed to Ibero-American repositories such as Dialnet, Latindex, Redalyc and Scielo, considering the period from 1968 to 2018, as well as the key words, although the specific the study was limited to the design of the research, suggesting the inclusion of resilience as an emergent factor of the sustainable water agenda.

Keywords: Teledirection. Horizontality. Microsystem. Heuristic. Periphery.

\section{Introducción}

El objetivo del presente trabajo fue especificar un modelo para el estudio del establecimiento de la agenda en torno a la sustentabilidad hídrica, considerando una revisión de fuentes indexadas a repositorios de Iberoamérica como Dialnet, Latindex, Redalyc y Scielo, así como las palabras claves de "agenda", "enmarcado", "sustentabilidad", "recursos hídricos" con la finalidad de anticipar 
escenarios de ingobernabilidad y gobernanza entre los actores civiles y políticos, así como entre los sectores públicos y privados.

El establecimiento de la agenda, para los fines del presente trabajo, alude a un proceso en el que los medios de comunicación; radio, cine, televisión, prensa o Internet, generan temas convergentes con las ideas generales de sus audiencias con la finalidad de anticipar un escenario probable de discusión, acuerdos y responsabilidades, pero la diversidad informativa de los medios, así como la inconmensurabilidad de temas supone el establecimiento de multiagendas (Carreón, García y Morales, 2014).

Pues bien, las multiagendas emergieron con el advenimiento de Internet y principalmente de las redes digitales. Es el caso de Twitter, Facebook, WhatsApp, YouTube, SnapChat o Instagram donde prevalecen agendas centradas en ejes más que en temas. De esta manera, los ejes de información refieren a la difusión de la horizontalidad, pero seguida de la verticalidad como sería el caso de una elección presidencial en el que los candidatos generan una imagen de proximidad hacia el electorado, pero una vez obtenido el puesto ejecutivo, o legislativo, emerge en los mismos medios la verticalidad a través de la obediencia a los cambios propuestos por el presidente, diputado o senador, o bien, la conformidad una vez que la corrupción política se ha establecido y consolidado (García, 2010).

Es así como las múltiples agendas de sustentabilidad hídrica refieren a políticas centradas en la escasez, el desabastecimiento, la insalubridad y la carestía que legitimarán programas de oferta estatal más que de atención focalizada (García, 2011a, 2011b).

Por consiguiente, la literatura especializada sobre las problemáticas de las múltiples agendas reflejará el contexto y el escenario de diversidad informativa, temática y verticalidad-horizontalidad. Es así como un procesamiento de los contenidos de la literatura consultada permitirá observar las diferencias y las similitudes entre los actores políticos y sociales, así como entre los sectores públicos y privados (García, 2012a, 2012b). 


\section{Estudios de las múltiples agendas de sustentabilidad hídrica}

Las múltiples agendas de sustentabilidad hídrica refieren a una diversidad informativa que se disemina en las redes digitales con la finalidad de legitimar la verticalidad o la horizontalidad de las relaciones entre gobernantes y gobernados, pero en medio de tal sinergia está la literatura que ha observado sistemáticamente las asimetrías entre los actores (véase Tabla 1).

Tabla 1.

Estudios de la multiplicidad de agendas de sustentabilidad hídrica

\section{Año Autor Hallazgo}

1991 Ajzen (1991)

Estableció el efecto deliberado, planificado y sistemático de la información sobre las expectativas de control. En el marco de la psicología de los medios de comunicación, sus efectos propagandísticos en la formación de creencias y actitudes, los estudios del establecimiento de la agenda plantean que existe una relación causal entre los contenidos de los medios de comunicación y los temas de interés de la opinión pública.

2006 Becerra, Sainz y Encontraron una relación directa, negativa y significativa entre la Muñoz (2003) demanda de agua y el incremento de las tarifas. En materia de políticas públicas, el sistema de cobro, principal estrategia e instrumento gubernamental para la sustentabilidad de la demarcación, propició un aumento de las movilizaciones por el abastecimiento regular de agua según la prensa de circulación nacional. 
analizables como flujos energéticos en los que la entrada de energía (input) redistribuye las funciones en el sistema a un grado tal que los estabiliza o desestabiliza según sea el caso. Tal intercambio energético puede implicar un disturbio energético. En este sentido, un sistema codifica y decodifica sus canales de distribución para hacer frente a la demanda decreciente o creciente. De este modo, la producción de un sistema está en función del input energético. La TSG fue la primera propuesta para el estudio de la comunicación humana. Puesto que cada ser viviente demanda, procesa y consume, es menester considerar a los seres vivos como sistemas no sólo de energía, sino también de tecnología, información, comunicación y actitud.

1977 Bronfenbrenner (1977)
Plantea que el desarrollo evolutivo requiere de actos significativos relacionados con experiencias personales o grupales. Cada acto es indicador del desarrollo humano. Incluso, aquellos actos que son significativos se circunscriben al desarrollo individual en los que el entorno, es decir, las relaciones entre individuos y grupos determinan los siguientes actos de la persona. Por ello, la Teoría de la Ecología del Desarrollo (TED) plantea que, si analizamos los actos deliberados de las personas más que sus discursos, encontraremos el indicador de cada subsistema.

1989 Cacioppo y Petty Encontraron que a medida que los mensajes de inseguridad son (1989) emitidos por los medios de comunicación, influyen de un modo automático en la memoria y las decisiones de las personas. La continua difusión de la inseguridad propiciaría en las audiencias una dependencia a corto, mediano y largo plazo en los medios de 
comunicación por parte de aquellas personas que han sido persuadidas y han incorporado la información circundante en sus decisiones y acciones cotidianas. En tal sentido, la Teoría de la Probabilidad de la Elaboración (TPE) sostiene que la información es procesada en rutas periféricas relacionadas con decisiones espontáneas y comportamientos improvisados, así como rutas centrales implicadas con decisiones y acciones deliberadas. Tales procesamientos de información se denominaron como "necesidad de cognición" definida como el procesamiento sesgado de información que llevan a cabo los individuos al momento de ser persuadidos por un mensaje.

1977 Fazio, Zanna y Consideraron que la formación de actitudes hacia los medios de Cooper (1977) comunicación y sus mensajes correspondientes implicó una activación directa de imágenes y frases con la memoria procedimental. A medida que los mensajes eran transmitidos, su duración y repetición parecieron activar experiencias previas y con ello formaban actitudes y acciones espontáneas sin requerir de algún cálculo mental o razonamiento inquisitivo.

1972 McCombs y Shaw Plantearon la Teoría del Establecimiento de la Agenda (TEA) para (1972) explicar el sesgo informativo y la influencia de la cobertura mediática respecto a los temas más comentados por la opinión pública.

\section{McCombs (1996)} Plantea una explicación al por qué los medios de comunicación sesgan sus notas informativas y determinan los temas de discusión en la opinión pública. La TEA sostiene que la información de los hechos es procesada por los profesionales de la comunicación, publicidad y mercadotecnia para modificar los contenidos en función de políticas 
internas. La TEA advierte que cada mensaje sesgado no basta para ser un indicador de manipulación, sólo se trata de hecho transformado en frase, spot, imagen, noticia u opinión. En este sentido, el sesgo informativo alude a la apreciación de un tercer elemento afectado por la relación medios de comunicación y audiencias. Se trata de otros medios de comunicación en competencia con el medio de mayor rating y que a la vista de su competencia, es definido como un medio controlador y manipulador de audiencias.

1995 McCombs y Hua Consideran a los medios de comunicación como un poder central (1995) capaz de definir los temas críticos de la agenda política. Es decir, las políticas públicas y los programas públicos estarían determinados por la difusión de problemáticas que impactarían en las audiencias y construirían un imaginario y zozobra social que la clase política tomaría en cuenta al momento de definir las partidas presupuestales antes, durante y después de los comicios locales o federales.

1981 McCombs, Cole, Sostienen que la emergencia de la inseguridad cibernética y la Stevenson y Shaw videovigilancia digital parecen haber rebasado a la TEA. A medida que (1981) los sistemas informativos y comunicativos se digitalizan y virtualizan, los presupuestos de la TEA parecen explicar hechos homogéneos que en la sociedad de la información se han diversificado hasta un punto tal que hace necesario el replanteamiento de la TEA.

1998 McCombs, Lllamas, Aseguran que la relación entre los medios de comunicación y el López y Rey (1998) Estado es explicada a través de la ciudadanía. Es decir, la formación y desarrollo de la opinión pública, durante las cuatro últimas décadas del siglo XX, había sido explicada por la incidencia de la propaganda difundida en cine, prensa, radio o televisión. Sainz y Becera (2003) 
han establecido el enmarcado de nulidad de conflictos por parte de la prensa escrita en torno a las relaciones asimétricas entre autoridades y usuarios. Tal hallazgo de las observaciones de intensificación de conflictos en la demarcación abona al primer postulado de la Teoría del Establecimiento de la Agenda en el que se advierte un sesgo noticioso que influye en la agenda política a través de la opinión pública.

2003 Sainz y Becerra Realizaron un estudio descriptivo sobre el contenido de las notas de (2003) periódicos y encontraron una tendencia creciente de las movilizaciones ciudadanas. Los usuarios pasaron de manifestaciones verbales a confrontaciones directas con las autoridades por el cierre de avenidas como medida de presión para el abastecimiento regular de agua. Al respecto, mediante un modelo de regresión,

1998 Sartori (1998) Sostiene que decir que los medios de comunicación, principalmente la televisión, manipulan las audiencias hasta convertirlas en consumidores cautivos de los más oscuros intereses es el argumento de la Teoría de la Sociedad Teledirigida (TST). Desde el proceso de socialización más que de recepción de los medios, los efectos mediáticos implican información aprendida por las audiencias con base en imágenes más que discursos. La imagen parece haber desplazado a los discursos. Aunados a la imagen, los spots sustituyeron a los discursos sociopolíticos. Cada relación unidireccional entre imagen y espectador devela una sociedad teledirigida, manipulada, cooptada, trastocada y socavada de sus tradiciones para homogeneizar su consumismo. Tal relación entre spots y consumidores permiten afirmar que la influencia de la 
televisión la hace insustituible incluso por Internet.

1986 Tversky

Kahneman (1986) y Proponen un modelo para el estudio del procesamiento de información automático y sistemático. En tal modelo, la experiencia de recepción de información activa decisiones comunicativas que incidirán en el comportamiento prospectivo. La espontaneidad de un mensaje podría tener una relación directa con el razonamiento heurístico. En este sentido la Teoría de las Decisiones Prospectivas (TDP) sostiene que, en situaciones de incertidumbre, las decisiones de los individuos son influidas por "atajos mentales" en los que una noticia sobre inseguridad activaría la desconfianza, el miedo o el enojo.

Fuente: Elaboración propia

Las múltiples agendas en general y las agendas hídricas en particular refieren a una lógica de verosimilitud y verificabilidad que consiste en la difusión de temas que pueden o no coincidir, pero convergen en cuanto al tipo de audiencia al que van dirigidos como es el caso de la lógica de verosimilitud orientada hacia un público no lector ni reflexivo, pero que adoptará las ideas generales de seguridad, obediencia y conformidad con respecto a la verticalidad que requiere un actor político o sector público a fin de poder gobernar sin la intromisión de la ciudadanía más que en cuanto a consultas o elecciones (García, 2013a, 2013b).

Pues bien, frente a la lógica de verosimilitud que difunde un Estado rector y omnipresente en la vida privada, los medios de comunicación diseminan en menor medida una lógica de verificabilidad para quienes diseccionan y comparan la información. Se trata de un público centrado en los datos y cifras más que en las imágenes propias de la lógica de verosimilitud (García, 2014). 


\section{Método}

¿Cuáles son los ejes, temas y lógicas en el proceso de establecimiento de la agenda de las fuentes indexadas a repositorios de Iberoamérica con respecto a la sustentabilidad hídrica?

Supuesto de simplicidad: Los ejes, temas y lógicas que los medios usan para diseminar la escasez, desabastecimiento, insalubridad y carestía legitiman políticas de oferta en urbes donde prevalecen audiencias informadas en función de la proximidad electoral.

Supuesto de complejidad: La multiplicidad de agendas más que converger, emergen no sólo de los medios de comunicación o las redes digitales sino, además subyacen de las audiencias que buscan cada vez más alejarse del escenario de escasez, desabastecimiento, insalubridad y carestía para alcanzar un confort a través del uso excesivo de los recursos y servicios hídricos sin importar los derechos de las actuales generaciones rurales o semiperiféricas, así como de las que habitarán esos lugares en el futuro.

Se llevó a cabo un estudio no experimental, transversal, exploratorio y documental con una selección no probabilística de fuentes indexadas a repositorios de Iberoamérica como Dialnet, Latindex, Redalyc y Scielo, considerando las palabras claves de "agenda", "sustentabilidad" y "recursos hídricos", así como el periodo de 1968 a 2018.

Se utilizó una matriz de análisis de contenido en el que a partir de la técnica Delphi se procesó la información en seis fases: 1) síntesis de datos, 2) inferencia de tendencias, 3) contextualización de la información, 4) inferencia de escenarios posibles, 5) comparación de los escenarios y 6) integración de los datos (Krippendorff, 1989, 2005; Chihú, 2011).

En cada fase, se le asignó un -1 a la información que fue evaluada por jueces expertos como ejemplo de una lógica de verificabilidad, con un 0 a la información sin relación con la problemática y con 1 a la información asociada a la lógica de la verosimilitud.

Se sumaron las evaluaciones de los 10 jueces para cada una de las fuentes consultadas, generándose un índice de mediatización a partir del cual se especificaron las relaciones entre las 
variables que la literatura reportó como determinantes o indicativas del establecimiento de múltiples agendas de sustentabilidad hídrica.

\section{Resultados}

La Tabla 2 muestra las relaciones de dependencia o reflejantes entre los factores e indicadores relativos al estudio del establecimiento de la agenda en general y del establecimiento de la agenda hídrica en particular.

Tabla 2. Análisis de contenido

\section{Año Autor Especificación}

1968 Bertalanffy (1968) Codificación $\rightarrow$ Intercambio (comunicación) $\rightarrow$ flujos energéticos $\leftarrow$ disturbio

1972 McCombs y Shaw (1972) Difusión sesgada $\rightarrow$ encuadre informativo $\rightarrow$ establecimiento de agenda

1977 Bronfenbrenner (1977) Actos morales $\rightarrow$ exosistema $\rightarrow$ mesosistema

microsistema $\leftarrow$ actos moleculares

1977 Fazio, Zanna y Cooper Recuerdos a corto plazo $\rightarrow$ actitud $\rightarrow$ conducta (1977)

1981 McCombs, Cole, Stevenson Videovigilancia $\rightarrow$ homogeneidad informativa y Shaw (1981) diversificación de la agenda

1986 Tversky y Kahneman (1986) Heurísticos $\rightarrow$ toma de decisión $\rightarrow$ propensión al riesgo

1989 Cacioppo y Petty (1989) Necesidad de cognición $\rightarrow$ actitudes $\rightarrow$ elaboración central (racionalidad) $\leftrightarrow$ elaboración periférica (emocional)

1991 Ajzen (1991) Difusión mediática $\rightarrow$ expectativas de control $\rightarrow$ creencias 


\section{actitudes $\rightarrow$ intenciones $\rightarrow$ comportamiento}

1995 McCombs y Hua (1995)

Difusión de políticas $\rightarrow$ establecimiento de agenda

emociones de las audiencias

1996 McCombs (1996))

Diversidad informativa

Sesgo informativo toma de decisiones

\section{McCombs, Lllamas, López y Formación de la opinión pública $\rightarrow$ propaganda}

Rey (1998)

2003 Sainz y Becerra (2003)

Enmarcado

agenda establecida

legitimación de asimetrías

1998 Sartori (1998) teledirección de imágenes emociones $\rightarrow$ agenda política

2006 Becerra, Sainz y Muñoz

Demandas de agua $\rightarrow$ incremento de tarifas movilizaciones (2003) conflictos

Fuente: Elaborada con los datos del estudio

Las agendas múltiples parecen emerger luego de que los medios de comunicación han teledirigido una lógica de verosimilitud sustentada en imágenes como serían los casos de corrupción en videos de denuncia o audios en candidatos o personas cercanas a ellos para reducir las preferencias e intenciones de voto a favor de su propuesta.

Especial interés suscita el hecho de que las agendas múltiples estén asociadas a los actores molares que no sólo determinan una intención o el voto hacia una opción partidista o candidatura sino, además generan una propensión a la adhesión ideológica, o bien, la promoción individual de esa opción a través de discursos como "más vale corrupto por conocido que por conocer", "entre políticos te veas", o "el político que no hace transa no avanza".

Se trata de un proceso complejo que va más allá del establecimiento de agendas múltiples y que alude a la parte cualitativa del electorado en los comicios y en la proximidad de las elecciones. Los 
actos molares o actos significativos de apoyo a un candidato, partido o coalición son determinantes de actitudes, intenciones y comportamientos del electorado influido por la verosimilitud de imágenes para con el electorado que indaga y compara la información.

De esta manera, la especificación del modelo incluye cinco factores en el que el establecimiento de las agendas múltiples sería explicado por la verticalidad y horizontalidad informativa, el sesgo de difusión, la teledirección emocional, las actitudes e intenciones (véase Figura 1).

Figura 1. Especificación de un modelo para el estudio de la agenda hídrica sustentable

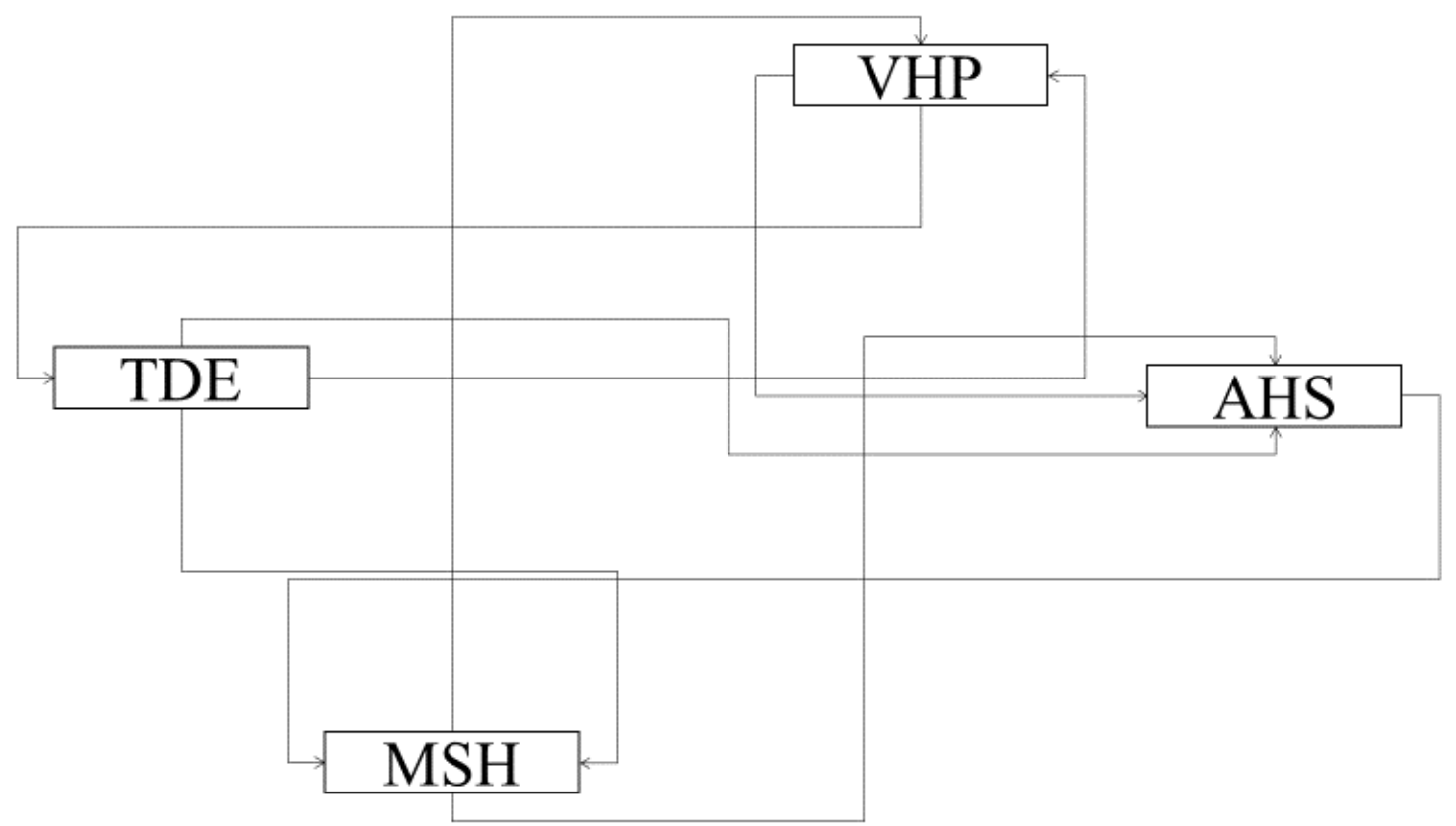

AHS = Agenda Hídrica Sustentable, VHP = Verificabilidad Horizontal Periférica, $\mathrm{MSH}=$ Micro-Sistema Heurístico, TDE = Tele Dirección Emocional

Fuente: Elaboración propia

La propuesta destaca los procesos emocionales, horizontales, periféricos, verosímiles, molares y heurísticos que explican, si bien la multiplicidad de agendas, todas y cada una desde la teledirección sesgada de los medios, la proximidad de actores políticos a las necesidades sociales, la recepción periférica de las audiencias, la lógica de verosimilitud de las imágenes, el significado molar de los 
actos significativos y el procesamiento automático de disposiciones en la toma de decisiones y acciones.

Es el caso de la teledirección de un candidato enfocada en su imagen como servidor público, la recepción de esas imágenes por audiencias que creen en la política libre de corrupción, la verosimilitud de la declaración del patrimonio del partido o el candidato y los actos significativos de proximidad a la familia del electorado determinarán un procesamiento automático de simpatía y elección.

No obstante que la diversidad de imágenes alrededor de un candidato o partido, así como la heterogeneidad de sus propuestas en diferentes medios, prevalece una propensión a la teledirección emocional, horizontal, periférica, molar y heurística orientada hacia las audiencias poco reflexivas de su situación y consumidoras de imágenes.

\section{Discusión}

El aporte del presente trabajo al estado de la cuestión radica en la especificación de un modelo considerando una revisión del estado de la cuestión, así como la codificación de información actualizada sobre la agenda de sustentabilidad hídrica, pero el tipo de estudio no experimental, el tipo de muestreo no probabilístico y el tipo de análisis de contenido limitan la especificación al escenario de la investigación; sugiriendo la inclusión de otros factores como es el caso del establecimiento de tarifas y tecnología para mejorar la calidad del servicio público.

García (2018a, 2018b) especificó un modelo para el estudio de discursos y narrativas en torno al derecho al acceso y consumo de agua para interpretar las narrativas sobre la agenda centrada en el incremento de tarifas más que en la insalubridad en el que encontró la preocupación mayoritaria de la literatura especializada frente a la carestía que fue la difusión intensiva de la prensa.

En el presente trabajo se evidenció la prevalencia de la teledirección emocional en la que la problemática de escasez, desabastecimiento, insalubridad y carestía fue asimilada por una serie de 
imágenes que determinarían el procesamiento circunvecino de los datos y el empleo consecuente de una lógica de verosimilitud para orientar la opinión pública hacia la calidad del servicio y la legitimación del incremento de tarifas, así como de la eliminación de subsidios.

Juárez, Bustos, Quintero, García, y Espinoza, (2018) revisaron y especificaron un modelo para el estudio de la gobernanza de la sustentabilidad hídrica centrada en la reutilización cooperativa, aunque sin criterios de selección que aludieran a los repositorios de Iberoamérica, destacan la importancia de la difusión, la transparencia, el acceso y la discusión informativa para el establecimiento de una agenda y toma de decisiones concertadas con las autoridades locales y federales.

En el presente trabajo, la verticalidad horizontal periférica fue incluida en la especificación del modelo con la finalidad de discutir la prevalencia de la teledirección emocional ante la proximidad electoral. En tal sentido, la gobernanza de la sustentabilidad hídrica no sólo depende del sesgo informativo sino de su difusión en imágenes para asociarla con heurísticos de responsabilidad como sería el caso de "el agua es mi derecho y debe ser gratuita para todos".

Quintero, García, Rivera, Sandoval, Figueroa y Molina (2018) especificaron un modelo para el estudio de la conciencia de la sustentabilidad hídrica en el que el ámbito local sería reducido a microsistemas de consumidores y administradores de la agenda local, pero no ya desde un sentido comunitario ni público sino desde el ámbito de los bienes comunes.

En el presente estudio se plantea el microsistema como un entorno de razonamientos automáticos o heurísticos que empatan con la teledirección emocional y la verificabilidad horizontal periférica como determinantes de la agenda hídrica sustentable.

Sin embargo, se recomienda la inclusión de la resiliencia como factor reflejante de la agenda hídrica sustentable ya que, en la medida en que se exacerban los conflictos entre autoridades y usuarios, la resiliencia parece emerger como una instancia de ingobernabilidad más que de gobernanza (Sandoval, Carreón, García, Quintero y Bustos, 2017; Sandoval, Bustos y García, 2018). 


\section{Conclusión}

El objetivo del presente trabajo fue especificar un modelo para el estudio de la agenda hídrica sustentable, considerando la inclusión de factores que la literatura consultada ha identificado como la teledirección emocional, el microsistema heurístico y la lógica de verificabilidad horizontal con procesamiento periférico de datos. Empero, el tipo de estudio, muestreo y análisis limitaron la especificación al escenario de la investigación, sugiriendo la inclusión del factor de resiliencia comunitaria.

\section{Referencias}

Ajzen, I. (1991). The Theory of Planned Behavior. Organizational Behavior and Human Decision Processes. 50, 179-211

Becerra, M., Sainz, J. y Muñoz, C. (2006). Los conflictos por agua en México. Diagnóstico y análisis. Gestión y Política Pública. 15, 111-143

Bertalanffy, L. (1968). General System Theory: Foundations, Development, Applications. New York: George Braziller

Bronfenbrenner, U. (1977). Toward an experimental ecology of human development. American Psychologist. 32, 523-530

Cacioppo, J. \& Petty, R. (1989). Effects of message repetition on argument processing, recall and persuasion. Basic and Applied Social Psychology. 10, 3-12

Carreón, J., García, C. y Morales, M. L. (2014). Hacia una administración consensuada de los recursos hídricos en ecociudades. Interdisciplinaria, 31 (1), 163-174

Chihú, A. (2011). El framing de la prensa. México: Porrúa-Uam

Fazio, R., Zanna, M. \& Cooper, J. (1977). Dissonance and self perception: an integrative view of each theory's proper domain of application. Journal of Experimental Social Psychology. 13, 464-479

García, C. (2010). La exclusión hidrológica. Revista Interdisciplinar Entelequia, 11, 41-59 
García, C. (2011a). Mediatización de la participación hídrica en Iztapalapa. En J. Pihedraita (coord.). Gestión social para el desarrollo humano. (pp. 521-547). Bogota: UCMC

García, C. (2011b). Teorías psicosociales para explicar los conflictos derivados del abastecimiento de agua en México, Distrito Federal. Revista Pampedia, 8, 56-68

García, C. (2012a). Hidroexclusión. Análisis de los factores psicosociales que impiden la sustentabilidad hídrica. Málaga: Universidad de Málaga

García, C. (2012b). Los estilos de vida en torno a las problemáticas hídricas. Sustentabilidades, 7, 8492

García, C. (2013a). Estructura de la percepción de riesgo en torno a la escasez y el desabasto de agua global y local. Xihmai, 15 (8) 95-118

García, C. (2013b). Los estudios psicológicos de la sustentabilidad hídrica. Aplicaciones al sistema tarifario de consumo. Revista de Ciencias Sociales, 139, 65-90

García, C. (2014). Teoría de la actitud hacia el consumo sustentable de agua. Sustentabilidades, 8, $33-41$

García, C. (2018a). Especificación de un modelo con fuentes de 1987 a 2017 para el estudio de la corresponsabilidad hídrica en una localidad del centro de México. Diálogos de Derecho y Política, 19, 18-38

García, C. (2018b). Interpretación de discursos en torno al subsidio de abastecimiento hídrico para la comprensión de narrativas tarifarias. Ciencias Sociales, 4 (2), 25-40

Juárez, M., Bustos, J. M., Quintero, M. L., García, C. y Espinoza, F. (2018). Gobernanza de la sustentabilidad hídrica: Especificación de un modelo para el estudio de la reutilización cooperativa. Invurnus, 13 (2), 33-43

Krippendorff, K. (1989). Content analysis. In E. Barnouw (Ed.). International Encyclopedia of Communication. (pp. 403-407) New York: Oxford University Press 
Krippendorff, K. (2005). The social construction of public opinion. In E. Wienand, Westerbarkey, J. \& Scholl, A. (Eds.). Kommunikation iiber kommunikation. Theorie, Methoden and Praxis. (pp. 129-149). Wiesbaden: VS-Verlag

McCombs, M. \& Hua, J. (1995). Capacity, diversity, and volatility of the public agenda. Trends from 1954-1994. Public Opinion Quarterly. 59, 495-525

McCombs, M. \& Shaw, D. (1972). The agenda setting function of mass media. Public Opinion Quarterly. 36, 176-187

McCombs, M. (1996). Influencia de las noticias sobre nuestras imágenes de nuestro mundo. En J. Bryant, Zillman, D. (coord.). Los efectos de los medios de comunicación. investigaciones y teorías. (pp. 13-34). Barcelona: Paidós.

McCombs, M., Cole, R., Stevenson, R. \& Shaw, D. (1981). Precision journalism: an emerging theory and technique of news reporting. Gazzette. 27, 21-34

McCombs, M., Llamas, J., López, E. \& Rey, F. (1998). Candidate images in spanish elections: second level agenda setting effects. Journalism \& Mass Communication Quarterly. 74, 703-717

Quintero, M. L., García, C., Rivera, B. L., Sandoval, F. R., Figueroa, O. y Molina, H. D. (2018). Modelo de conciencia para la sustentabilidad. Integración Académica en Psicología, 6 (16), 4-19

Sainz, J. y Becerra, M. (2003). Los conflictos por el agua en México. Gaceta de Ecológica. 67, 61-68 Sandoval, F. R., Bustos, J. M. y García, C. (2018). Contrastación exploratoria de un modelo de gobernanza de la sustentabilidad hídrica local. Revista Gestión de la Personas y Tecnología, 31, $72-87$

Sandoval, F. R., Carreón, J., García, C., Quintero, M. L. y Bustos, J. M. (2017). Modelo de los determinantes de la resiliencia a partir de la percepción de riesgo y estrés percibidos en relación con la gobernanza de la protección civil. Invurnus, 12 (1), 30-35

Sartori, G. (1998). Homo videns. Sociedad teledirigida. Madrid: Taurus

Tversky, A. \& Kahneman, D. (1986). Rational choice and the framing of decisions. The Journal of Business. 59, 251-258. 